\title{
Statistical learning in patients in the minimally conscious state
}

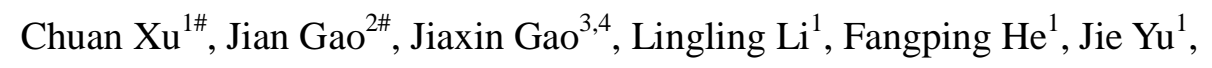

Yi Ling ${ }^{1}$, Hangcheng $\mathrm{Li}^{2}$, Jingqi $\mathrm{Li}^{2}$, Lucia Melloni ${ }^{5}$, Benyan Luo ${ }^{1 *}$, Nai Ding ${ }^{3,4^{*}}$

${ }^{1}$ Department of Neurology,

First Affiliated Hospital, School of Medicine,

Zhejiang University, Hangzhou 310003, China

${ }^{2}$ Department of Rehabilitation,

Hangzhou Mingzhou Brain Rehabilitation Hospital,

Hangzhou 311215, China

${ }^{3}$ Key Laboratory for Biomedical Engineering of Ministry of Education,

College of Biomedical Engineering and Instrument Sciences,

Zhejiang University, Hangzhou 310027, China

${ }^{4}$ Research Center for Advanced Artificial Intelligence Theory,

Zhejiang Lab, Hangzhou 311121, China

${ }^{5}$ New York University Comprehensive Epilepsy Center, 223 34th Street, New York, NY 10016, USA

${ }^{\#}$ Co-first author: Chuan $\mathrm{Xu}$, Jian Gao

"These authors contributed equally to this work.

*Corresponding author:

Nai Ding,

Email: ding_nai@zju.edu.cn

Key Laboratory for Biomedical Engineering of Ministry of Education, College of

Biomedical Engineering and Instrument Sciences, Zhejiang University, China 310027

Benyan Luo,

Email: luobenyan@zju.edu.cn

Department of Neurology, First Affiliated Hospital, School of Medicine, Zhejiang

University, China 310003 


\begin{abstract}
:
When listening to an unknown language, listeners could learn the transitional probability between syllables and group frequently co-occurred syllables into a whole unit. Such statistical learning ability has been demonstrated for both pre-verbal infants and adults, even during passive listening. Here, we investigated whether statistical learning occurred in patients in minimally conscious state (MCS) and patients emerged from the minimally conscious state (EMCS) using electroencephalography (EEG). We presented to participants an isochronous sequence of syllables, which were composed of either 2-word real phrases or 2-word artificial phrases that were defined by the transitional probability between words. An inter-trial phase coherence (ITPC) analysis revealed that the phrase-rate EEG response was weakened in EMCS patients compared with healthy individuals, and was even more severely weakened in MCS patients. Although weak, the phrase-rate response or its harmonics remained statistically significant in MCS patients, suggesting that the statistical learning ability was preserved in MCS patients. The word-rate response was also weakened with a decreased level of consciousness. The harmonics of the word-rate response, however, were more salient in MCS than EMCS patients in the alpha and beta bands. Together with previous studies, the current results suggest that MCS patients retain residual learning ability, which can potentially be harnessed to induce neural plasticity, and that different frequency bands are differentially related to the consciousness level.
\end{abstract}

Key words: statistical learning, disorders of consciousness, stimulus-locked activity 


\section{Introduction}

The ability to learn the statistical regularities in an environment is critical for the survival of biological organisms. Statistical learning has been demonstrated for different sensory modalities, tasks, and species [1] and hypothesized as a critical building block for higher-level cognitive functions [1, 2]. In the domain of language processing, it has been established that 8-month-old infants can learn to segment a sequence of syllables into multi-syllabic words by exploiting the transitional probability between syllables [3]. Behaviorally, both infants and adults rate the multi-syllabic words respecting the transitional probabilities they are exposed to as being more familiar than other combinations of syllables that while present in the stimulus materials do not respect the transitional probabilities. It has been hypothesized that statistical learning is a fundamental mechanism for infants to discover larger linguistic units such as words and phrases from running speech.

For healthy infants and adults, statistical learning has been demonstrated during passive listening [3, 4] and can be enhanced when participants attend to the syllable sequence [5]. Nevertheless, it remains possible that participants spontaneously attend to the syllable sequence even during passive listening. Moreover, it is postulated that unlimited associative learning (UAL) provides a general marker of consciousness [6]. Therefore, here, we investigate whether statistical learning can occur in patients in a MCS state, who have minimal language ability, attention and low-level awareness. Since MCS patients can barely make behavioral responses, we objectively quantify whether they can achieve statistical learning using EEG.

When listening to a known language, cortical activity measured by EEG or MEG can track the rhythms of multiple levels of linguistic units such as syllables, words, and phrases [7, 8]. During statistical learning, cortical tracking of artificial words or phrases quickly emerge [9-11]. Since the word/phrase-tracking EEG/MEG response can be objectively measured without any behavioral response, it can be conveniently applied to study statistical learning in difficult-to-test populations. For example, a recent study [12] finds EEG evidence for statistical learning in preverbal infants. Another recent study finds that the EEG response tracking phrases is marginally significant when MCS patients listen to their native language [13]. Here, we apply the same EEG-based method to investigate whether statistical learning can occur in the MCS, comparing the EEG responses to known phrases and phrases acquired through statistical learning.

\section{Methods}

\section{Participants}

This study involved 19 MCS patients (14 males; $54.58 \pm 11.48$ years) and 22 EMCS (17 males; $53.32 \pm 12.16$ ) patients. The following inclusion criteria were used: (i) diagnosis with MCS, EMCS based on Coma Recovery Scale-Revised (CRS-R) assessments carried out by DoC experts [14]; (ii) more than 1 month since brain injury; (iii) age over 18 years; (iv) no history of hearing impairment before brain 
injury; (v) presence of the auditory startle reflex; (vi) no centrally acting drugs, neuromuscular function blockers, or sedation within 24 hours prior to the study; (vii) no obvious skull bone defects (CT); (viii) no history of neurodegenerative diseases such as Alzheimer's disease and Parkinson's disease before brain injury. The patients suffered from traumatic brain injury (TBI), anoxic brain injury, or cerebrovascular disease.

Twenty age-matched healthy individuals ( 3 males; $50.45 \pm 8.87$ ) with no history of neurological diseases were also included. There was no significant age difference between healthy individuals and either of the 2 patient populations (one-way ANOVA, $\mathrm{P}=0.485$ ). The study was approved by the Ethical Committee of the First Affiliated Hospital of Zhejiang University, and by Hangzhou Mingzhou Brain Rehabilitation Hospital. Written informed consent was provided by the participants or their legal guardians for the experiments and the publication of their individual details in this study.

\section{Stimuli}

The stimulus consisted of an isochronous sequence of monosyllabic Chinese words. Two conditions were presented. In the real phrase condition, the monosyllabic words constructed 4 common 2-word phrases, i.e., 'wake up', 'go home', 'eat rice', and 'be quick'. In the artificial phrase condition, the monosyllabic words constructed 4 artificial phrases that were reversed real phrases, i.e., 'up wake', 'home go', 'rice eat', 'quick be'. None of the artificial phrases were meaningful expressions in Chinese.

Monosyllabic words were individually generated using an artificial speech synthesizer and adjusted to the same intensity and the same duration, i.e., $500 \mathrm{~ms}$, following the procedure described in Ding et al. (2016) [7]. In previous studies, the syllable duration was between 250 and $330 \mathrm{~ms}[13,15]$, here we further slowed down the stimulus since DoC patients might not be able to follow speech at a normal rate. When constructing the sequences, the synthesized monosyllabic words were directly concatenated, without any additional pause in between. Therefore, monosyllabic words and phrases were isochronously presented at $2 \mathrm{~Hz}$ and $1 \mathrm{~Hz}$, respectively.

\section{Procedures}

All participants passively listened to isochronous speech sequences while their EEG responses were recorded. All participants had their eyes open at the beginning of the experiment. Healthy individuals and EMCS patients were asked to keep still during the experiment. No other tasks instructions were given. Each condition was composed of 108 trials, and each trial consisted of 11 phrases (11s in duration). All trials in each condition were presented with a randomized order. The real and artificial phrase conditions were presented successively and the order was counterbalanced across participants within each participant group.

\section{EEG recording and preprocessing}

EEG signals were recorded using a 64-electrodes BrainCap (Brain Products DmbH, 
Munich, Germany), and one electrode was placed under the right eye to record the electrooculogram (EOG). EEG signals were referenced online to $\mathrm{FCz}$, but were referenced offline to the average of the bilateral mastoids. The EEG signals were filtered online with a $50-\mathrm{Hz}$ notch filter to remove line noise (12th order zero-phase Butterworth filter), a low-pass antialiasing filter (70-Hz cutoff, 8th order zero-phase Butterworth filter), and a high-pass filter to prevent slow drifts $(0.3-\mathrm{Hz}$ cutoff, 8 th order zero-phase Butterworth filter). The signals were sampled at $1 \mathrm{kHz}$ and down-sampled to $80 \mathrm{~Hz}$. EOG artifacts were regressed out based on the least-squares method. The EEG signal was processed following the procedure in Zou et al. (2021) [16]. All preprocessing and analyses in this study were conducted in the MATLAB software (The MathWorks, Natick, MA).

\section{Frequency-domain analysis}

Each trial was $11 \mathrm{~s}$ in duration but in the frequency-domain analysis the first second of recording was discarded to remove the onset response. The remaining 10-s of data were transformed into the frequency domain using discrete Fourier transform (DFT), resulting in a frequency resolution of $0.1 \mathrm{~Hz}$. The ITPC was defined as:

$$
C_{f}=\left(\sum_{t=1}^{T} \cos \left(\alpha_{f t}\right)\right)^{2}+\left(\sum_{t=1}^{T} \sin \left(\alpha_{f t}\right)\right)^{2}
$$

where $\alpha_{f t}$ denoted the DFT phase at frequency $f$, and $C_{f}$ denoted the inter-trial phase coherence (ITPC). A higher ITPC value indicated that the response phase was consistent across trials. The ITPC at each frequency was further normalized by subtracting the mean ITPC value averaged over 2 neighboring frequency bins..

\section{Statistics}

Phase coherence: This study used bias-corrected and accelerated bootstrap for all significance tests [17]. In the bootstrap procedure, all the participants were resampled with replacement $10^{4}$ times. The chance-level phase coherence for each target frequency was the average of the phase coherence between 0.6 and $39.5 \mathrm{~Hz}$ ( 389 frequencies were used in total, $1 / 10 \mathrm{~Hz}$ for each bin). For the significance tests for the target peaks, such as $1 \mathrm{~Hz}, 2 \mathrm{~Hz}, 3 \mathrm{~Hz}, 4 \mathrm{~Hz} \ldots . .30 \mathrm{~Hz}$, the response amplitude at the peak frequency was compared with the mean amplitude of the 389 frequency bins. If the phase coherence at target frequency was stronger than the mean coherence of the mean coherence $N$ times in the resampled data, the significance level could be calculated as $(N+1) / 10001$.

Bootstrap: For the unpaired comparisons between groups, we also used bias-corrected and accelerated bootstrap [17]. The data from each group were resampled with replacement 10000 times. This comparison was one-sided. If in $N$ out of 10000 times, the mean in one group was greater (or smaller) than the other group, the significance level was $(N+1) / 10001$.

\section{Results:}


We analyzed the EEG responses to real and artificial phrases in 3 groups of participants, i.e., MCS patients, EMCS patients, and healthy individuals. Since the monosyllabic words were presented at an isochronous rate, the neural responses to words and the 2-word phrases were frequency tagged at $2 \mathrm{~Hz}$ and $1 \mathrm{~Hz}$, respectively (Fig. 1). For real phrases, previous studies have shown that EEG activity can track both the rhythms of words and phrases [7,13]. The artificial phrases were unknown to the participants at the beginning of the experiment but could be learned via statistical learning at least for healthy individuals [3] and led to a phrase-tracking neural response. We would analyze in the following whether the word and phrase responses were present in DoC patients and tested whether the strength of these responses differ across participant groups.

We first evaluated ITPC spectrum for healthy individuals. In this study, the ITPC at each frequency was always normalized by subtracting the mean ITPC averaged over two neighboring frequencies. As shown in Fig. 2, significant response peaks were observed at the word rate (i.e., $2 \mathrm{~Hz}$ ) and the phrase rate (i.e., $1 \mathrm{~Hz}$ ) in both the real-phrase condition $(2 \mathrm{~Hz}: \mathrm{P}=0.0009$, false discovery rate $(\mathrm{FDR})$-corrected; $1 \mathrm{~Hz}$ : $\mathrm{P}$ $=0.0009$, FDR-corrected $)$ and the artificial-phrase condition $(2 \mathrm{~Hz}: \mathrm{P}=0.0006$, FDR-corrected; $1 \mathrm{~Hz}$ : P $=0.0006$, FDR-corrected). Furthermore, significant responses were observed at frequencies that were harmonically related to the word and phrase rates. The harmonics were salient at 4 and $6 \mathrm{~Hz}$, and remained clearly observable above $10 \mathrm{~Hz}$. For EMCS patients, words-rate and phrase-rate responses were also significant in both the real $(2 \mathrm{~Hz}: \mathrm{P}=0.0015$, FDR-corrected; $1 \mathrm{~Hz}: \mathrm{P}=0.0266$, FDR-corrected) and artificial phrase conditions (2 Hz: $\mathrm{P}=0.0425$, FDR-corrected; 1 Hz: P $=0.0266$, FDR-corrected). Similarly, significant responses were observed at frequencies that were harmonically related to the word and phrase rates.

For MCS patients, a significant phrase-rate response peak was observed in the real-phrase condition ( $1 \mathrm{~Hz}: \mathrm{P}=0.0224$, FDR-corrected), but not in the artificial-phrase condition ( $\mathrm{P}=0.6498$, FDR-corrected). Nevertheless, significant neural responses were observed at frequencies that were harmonically related to the word-rate in the artificial-phrase condition. The odd-order harmonics of the phrase-rate response, e.g., the 7-Hz, 9-Hz, and 15- $\mathrm{Hz}$ responses $(\mathrm{P}=0.0240,0.0240$, and 0.0010, FDR-corrected, respectively), could not be explained by the harmonics of the word-rate response and therefore demonstrated that the brain could encode features related to the artificial phrases in the MCS state.

In the following, we separately analyzed the harmonics that could only be caused by the phrase-rate response, i.e., the responses at $3 \mathrm{~Hz}, 5 \mathrm{~Hz}, 7 \mathrm{~Hz}$, etc., and the harmonics that could be caused by both the phrase- and word-rate responses, i.e., the responses at $2 \mathrm{~Hz}, 4 \mathrm{~Hz}, 6 \mathrm{~Hz}$, etc. These two kinds of harmonics were separately referred to as odd-order harmonics and even-order harmonics. Furthermore, since there were a large number of harmonics, we grouped them into delta/theta-band harmonics (4-7 Hz), alpha-band harmonics $(8-13 \mathrm{~Hz})$, and beta-band harmonics 
(14-30 Hz). The harmonics falling into each band were averaged. As shown in Fig. 3, in the artificial-phrase condition, the mean ITPC of the odd-order harmonics in MCS patients was significant in all 3 bands $(\mathrm{P}=0.0046,0.0174$, and 0.0174 , for the theta, alpha, and beta bands, respectively FDR-corrected). In the real-phrase condition, the mean ITPC of odd-order harmonics in MCS patients was also significant in beta band $(\mathrm{P}=0.0062$, FDR-corrected $)$.

We then analyzed whether the response ITPC differed across participant groups or conditions (Table. 1). A 2-way ANOVA (condition by group) analysis revealed that the phrase-rate ITPC significantly differed across groups but not between conditions. No significant interaction was observed between the two factors. Similar results were observed for the word-rate ITPC and the harmonic responses. For the phrase/word-rate responses and their theta-band harmonics, the ITPC was generally higher for healthy individuals than the other two populations. For the alpha- and beta-band harmonics, however, the even-order harmonics was stronger for MCS than EMCS patients.

\section{Discussion}

Using a frequency-tagging approach, the current study demonstrated that statistical learning of artificial linguistic units can occur in a MCS state. Nevertheless, the neural representations of learned artificial phrases and real phrases were modulated by the consciousness state. Stimulus-locked neural responses in the delta and theta bands were enhanced by an increased level of consciousness. Stimulus-locked neural activity in the alpha and beta bands, however, showed a U-shaped curve, and is weakest in EMCS patients.

\section{Statistical learning in a MCS state}

Statistical learning has been hypothesized as a fundamental mechanism for infants to learn the boundaries between words [1, 18]. It is established that, in the absence of prosodic cues related to word boundaries, infants could learn to segment a sequence of syllables into words $[3,4,19]$. For visual sequences, it is also shown that probabilistic regularities between items can be detected by both adults and infants [20-22]. Although SL is widely studied using behavioral and neural measures, a recent study has pointed out that most of these measures tend to be noisy and are only reliable at the group level [23]. Recent studies show that statistical learning engages widely distributed areas in cortex and also the hippocampus: The superior temporal gyrus primarily encodes transitional probabilities, inferior frontal gyrus and anterior temporal lobe primarily encodes ordinal position and identity, and the hippocampus primarily encodes identity [24]. Here, the transitional probability within each artificial phrase equaled to 1 , and therefore the artificial phrases can also be referred to as artificial words. We referred to them as artificial phrases to be consistent to the common real phrases. 
Previous studies suggest that, in healthy individuals, divided attention degrades but does not abolish the acquisition and consolidation of transitional probabilities [5, 25]. Furthermore, it is shown that sleeping neonates are able to automatically extract statistical properties of the speech input and thus detect the word boundaries in a continuous stream of syllables containing no morphological cues [26]. More recently, it is suggested that preverbal infants have the ability to track statistical regularities, infants and adults follow similar learning trajectories when tracking probability information among speech sounds [12]. These results indicate that although statistical learning can be modulated by attention it can occur largely automatically in healthy individual. The current study demonstrated that statistical learning can occur in patients in a MCS state, providing further evidence that statistical learning was a reliable process that occurs automatously. The phrasal response, however, was weaker in MCS patients than EMCS patients and healthy individuals, possibly reflecting disrupted frontal and parietal functions at reduced levels of awareness [27, 28].

\section{Low-frequency neural tracking of speech}

When listening to speech, cortical activity can concurrently track speech units of different sizes, e.g., syllables, words, phrases, and sentences. It has been shown that even when the boundary between linguistic units is not associated with statistical cues, cortical activity can still track these linguistic units [7]. Nevertheless, when the linguistic units are purely defined by statistical cues, cortical activity tracking these linguistic units can also gradually emerge $[9,10]$. Here, we presented both real phrases and artificial phrases that were purely defined by statistical cues, it was found that the phrasal-rate response to real and artificial phrases had comparable strength. This result suggested that when the number of phrases was limited $(N=4$ in the current study) the phrasal-rate response was primarily driven by statistical cues. When the number of phrases was large so that the same phrase rarely repeat, the phrasal-rate response was more likely driven by other processes such as syntactic processing.

\section{Low-frequency neural activity and DoC}

In the current study, the artificial phrases were not defined by prosodic features and could only be constructed by analyzing the statistical relationship between words. The real phrases could be parsed by either syntactic rules or by analyzing the statistical relationship between words. Therefore, neural tracking of artificial and real phrases cannot originate from neural encoding of acoustic features of speech but instead must reflect higher-level processes such as cortical encoding of statistical relationship between words or the neural construction of multi-word chunks. The result showed that low-frequency, i.e., 1-Hz, neural activity can track artificial and real phrases in healthy individuals and EMCS patients, but not in MCS patients.

This result was consistent with the hypothesis that slow cortical activity contributes to the emergence of consciousness [29] and attention [30], and was also consistent with previous results showing that MCS and UWS patients cannot track real spoken 
phrases $[13,15]$. Furthermore, the results were also consistent with previous findings that low-frequency neural tracking of phrases is disrupted by sleep and lack of top-down attention [31, 32]. The formation of slow oscillations relies on the balance between neural excitation and inhibition [33,34] and generally requires synchronization between large-scale neural networks $[35,36]$. Slow cortical activity might be a neural substrate to integrate information across broad cortical areas and therefore may contribute to the conscious experience, which is always a unitary and undivided whole $[37,38]$.

Here, an increase in delta- and theta-band activity is associated with an increase in consciousness level. In contrast, some previous studies have reported an increase in slow oscillations in anesthetized participants [39] or unresponsive participants [40, 41]. The slow oscillations in these studies, however, are generally spontaneous, non-stimulus-locked oscillations, instead of the stimulus-locked response analyzed in the current study. Therefore, it is possible that the ability to synchronize low-frequency neural activity to external stimulus, instead of the absolute power of low-frequency activity, is an index of consciousness level.

Prolonged disorders of consciousness (DoC) are defined as any disorder of consciousness that has continued for at least four weeks following sudden onset brain injury, includes patients in coma, VS/UWS, and MCS [42, 43]. It is established that high level, covert cognition may be present in patients whose bedside evaluation appears consistent with the vegetative state or minimally conscious state [44-46]. Identification of covert cognition in patients with prolonged DoC is important, as patients with covert consciousness (cognitive motor dissociation, CMD) have a better prognosis than other patients, determining residual cognition in these patients has its crucial impact on family counselling, decision-making and the design of rehabilitation programs [47-50]. Therefore, it is important to generalize diagnostic tools to identify CMD patients for patients with prolonged DoC. Currently, the covert consciousness is typically probed with paradigms that require the patient to follow repeated commands to imagine that they are moving. The high demands on cognitive ability result in low sensitivity in the aspect of detecting CMD [50]. In this study, we found that statistical learning abilities were preserved in consciousness perturbation, indirectly indicating that the EEG response during passive statistical learning may be a promising paradigm to detect residual high-level cognition in patients with DoC.

In conclusion, we found that statistical learning abilities was preserved in consciousness perturbation. Furthermore, the study shows that neural activity tracking spoken words and phrases showed a large number of harmonics in the theta, alpha, and beta bands. An increase in delta- and theta-band stimulus-locked neural activity and a decrease in alpha- and beta-band stimulus-locked neural activity are suggestive of an improvement of consciousness in DoC patients.

\section{Acknowledgements}


medRxiv preprint doi: https://doi.org/10.1101/2022.01.04.22268656; this version posted January 6, 2022. The copyright holder for this preprint

(which was not certified by peer review) is the author/funder, who has granted medRxiv a license to display the preprint in perpetuity.

All rights reserved. No reuse allowed without permission.

The authors would like to thank the patients, their families, and volunteers for their participation in this study. This work was supported by National Natural Science Foundation of China 81870817, Guangzhou Key R\&D Program of China 202007030005, National Key R\&D Program of China 2018YFA0701400, and supported by the MOE Frontier Science Center for Brain Science \& Brain-Machine Integration, Zhejiang University.

\section{Conflict of Interest}

There are no potential conflicts of interest relevant to this manuscript. 
medRxiv preprint doi: https://doi.org/10.1101/2022.01.04.22268656; this version posted January 6, 2022. The copyright holder for this preprint

(which was not certified by peer review) is the author/funder, who has granted medRxiv a license to display the preprint in perpetuity.

All rights reserved. No reuse allowed without permission.

\section{Reference}

1. Frost $\mathrm{R}$, Armstrong $\mathrm{BC}$, Christiansen $\mathrm{MH}$ : Statistical learning research: A critical review and possible new directions. Psychol Bull2019, 145(12):1128-1153.

2. Bogaerts L, Richter CG, Landau AN, Frost R: Beta-Band Activity Is a Signature of Statistical Learning. The Journal of neuroscience : the official journal of the Society for Neuroscience 2020, 40(39):7523-7530.

3. Saffran JR, Aslin RN, Newport EL: Statistical leaming by 8-month-old infants. Science (New York, NY) 1996, 274(5294):1926-1928.

4. Saffran JR, Johnson EK, Aslin RN, Newport EL: Statistical learning of tone sequences by human infants and adults. Cognition 1999, 70(1):27-52.

5. Batterink LJ, Paller KA: Statistical learning of speech regularities can occur outside the focus of attention. Cortex 2019, 115:56-71.

6. Ginsburg S, Jablonka E: The evolution of the sensitive soul: learning and the origins of consciousness. MIT Press, Cambridge 2019.

7. Ding N, Melloni L, Zhang H, Tian X, Poeppel D: Cortical tracking of hierarchical linguistic structures in connected speech. Nat Neurosci2016, 19(1):158-164.

8. Ding N, Melloni L, Yang A, Wang Y, Zhang W, Poeppel D: Characterizing Neural Entrainment to Hierarchical Linguistic Units using Electroencephalography (EEG). Frontiers in human neuroscience 2017, 11:481.

9. Getz H, Ding N, Newport EL, Poeppel D: Cortical tracking of constituent structure in language acquisition. Cognition 2018, 181:135-140.

10. Buiatti M, Pena M, Dehaene-Lambertz G: Investigating the neural correlates of continuous speech computation with frequency-tagged neuroelectric responses. 
Neurolmage 2009, 44(2):509-519.

11. Henin S, Turk-Browne NB, Friedman D, Liu A, Dugan P, Flinker A, Doyle W, Devinsky O, Melloni L: Learning hierarchical sequence representations across human cortex and hippocampus. Sci Adv 2021, 7(8).

12. Choi D, Batterink LJ, Black AK, Paller KA, Werker JF: Preverbal Infants Discover Statistical Word Patterns at Similar Rates as Adults: Evidence From Neural Entrainment. Psychol Sci2020, 31(9):1161-1173.

13. Gui P, Jiang Y, Zang D, Qi Z, Tan J, Tanigawa H, Jiang J, Wen Y, Xu L, Zhao J et al. Assessing the depth of language processing in patients with disorders of consciousness. Nat Neurosci2020, 23(6):761-770.

14. Kondziella D, Bender A, Diserens K, van Erp W, Estraneo A, Formisano R, Laureys S, Naccache L, Ozturk S, Rohaut B et al. European Academy of Neurology guideline on the diagnosis of coma and other disorders of consciousness. Eur J Neurol 2020, 27(5):741-756.

15. Sokoliuk R, Degano G, Banellis L, Melloni L, Hayton T, Sturman S, Veenith T, Yakoub KM, Belli A, Noppeney U et at. Covert Speech Comprehension Predicts Recovery From Acute Unresponsive States. Annals of neurology 2020.

16. Zou J, Xu C, Luo C, Jin P, Gao J, Li J, Gao J, Ding N, Luo B: theta-Band Cortical Tracking of the Speech Envelope Shows the Linear Phase Property. eNeuro 2021, 8(4).

17. Efron B, Tibshirani RJ: An introduction to the Bootsrtrap. Chapman and Hall/CRC, UK 1994. 
medRxiv preprint doi: https://doi.org/10.1101/2022.01.04.22268656; this version posted January 6, 2022. The copyright holder for this preprint (which was not certified by peer review) is the author/funder, who has granted medRxiv a license to display the preprint in perpetuity.

All rights reserved. No reuse allowed without permission.

18. Bogaerts L, Siegelman N, Frost R: Statistical Learning and Language Impairments:

Toward More Precise Theoretical Accounts. Perspect Psychol Sci 2021, 16(2):319-337.

19. Saffran JR, Newport EL, Aslin RN: Word Segmentation: The Role of Distributional Cues. Journal of Memory \& Language 1996, 35(4):606-621.

20. Fiser J, Aslin RN: Unsupervised statistical learning of higher-order spatial structures from visual scenes. Psycho/ Sci 2001, 12(6):499-504.

21. Fiser J, Aslin RN: Statistical learning of new visual feature combinations by infants. Proceedings of the National Academy of Sciences of the United States of America 2002, 99(24):15822-15826.

22. Wu R, Gopnik A, Richardson DC, Kirkham NZ: Infants leam about objects from statistics and people. Dev Psycho/2011, 47(5):1220-1229.

23. Pinto D, Prior A, Golumbic EZ: Assessing the sensitivity of EEG-based frequency-tagging as a metric for statistical learning. 2021.

24. Henin S, Turk-Browne NB, Friedman D, Liu A, Dugan P, Flinker A, Doyle W, Devinsky O, Melloni L: Learning hierarchical sequence representations across human cortex and hippocampus. bioRxiv 2020:583856.

25. Horvath K, Torok C, Pesthy O, Nemeth D, Janacsek K: Divided attention does not affect the acquisition and consolidation of transitional probabilities. Scientific reports 2020, 10(1):22450.

26. Teinonen T, Fellman V, Naatanen R, Alku P, Huotilainen M: Statistical language learning in neonates revealed by event-related brain potentials. BMC Neurosci 2009 , 
10:21.

27. Naci L, Cusack R, Anello M, Owen AM: A common neural code for similar conscious experiences in different individuals. Proceedings of the National Academy of Sciences of the United States of America 2014, 111(39):14277-14282.

28. Davis MH, Coleman MR, Absalom AR, Rodd JM, Johnsrude IS, Matta BF, Owen AM, Menon DK: Dissociating speech perception and comprehension at reduced levels of awareness. Proceedings of the National Academy of Sciences of the United States of America 2007, 104(41):16032-16037.

29. He BJ, Raichle ME: The fMRI signal, slow cortical potential and consciousness. Trends Cogn Sci2009, 13(7):302-309.

30. Schroeder CE, Lakatos P: Low-frequency neuronal oscillations as instruments of sensory selection. Trends Neurosci2009, 32(1):9-18.

31. Ding N, Pan X, Luo C, Su N, Zhang W, Zhang J: Attention Is Required for Knowledge-Based Sequential Grouping: Insights from the Integration of Syllables into Words. The Journal of neuroscience : the official journal of the Society for Neuroscience 2018, 38(5):1178-1188.

32. Makov S, Sharon O, Ding N, Ben-Shachar M, Nir Y, Zion Golumbic E: Sleep Disrupts High-Level Speech Parsing Despite Significant Basic Auditory Processing. The Journal of neuroscience : the official journal of the Society for Neuroscience 2017, 37(32):7772-7781.

33. Haider B, Duque A, Hasenstaub AR, McCormick DA: Neocortical network activity in vivo is generated through a dynamic balance of excitation and inhibition. The Journal 
of neuroscience : the official journal of the Society for Neuroscience 2006, 26(17):4535-4545.

34. Okun M, Lampl I: Instantaneous correlation of excitation and inhibition during ongoing and sensory-evoked activities. Nat Neurosci2008, 11(5):535-537.

35. He BJ, Snyder AZ, Zempel JM, Smyth MD, Raichle ME: Electrophysiological correlates of the brain's intrinsic large-scale functional architecture. Proceedings of the National Academy of Sciences of the United States of America 2008, 105(41):16039-16044.

36. Leopold DA, Murayama Y, Logothetis NK: Very slow activity fluctuations in monkey visual cortex: implications for functional brain imaging. Cereb Cortex 2003, $13(4): 422-433$.

37. Searle JR: Consciousness. Annual review of neuroscience 2000, 23:557-578.

38. Tononi G: Consciousness as integrated information: a provisional manifesto. Bio/ Bull 2008, 215(3):216-242.

39. Purdon PL, Pierce ET, Mukamel EA, Prerau MJ, Walsh JL, Wong KF, Salazar-Gomez AF, Harrell PG, Sampson AL, Cimenser A et al. Electroencephalogram signatures of loss and recovery of consciousness from propofol. Proceedings of the National Academy of Sciences of the United States of America 2013, 110(12):E1142-1151.

40. Chennu S, Finoia P, Kamau E, Allanson J, Williams GB, Monti MM, Noreika V, Arnatkeviciute A, Canales-Johnson A, Olivares F et al. Spectral signatures of reorganised brain networks in disorders of consciousness. PLOS Comput Biol 2014, 10(10):e1003887. 
41. Frohlich J, Toker D, Monti MM: Consciousness among delta waves: a paradox? Brain : a journal of neurology 2021.

42. Giacino JT, Katz DI, Schiff ND, Whyte J, Ashman EJ, Ashwal S, Barbano R, Hammond FM, Laureys S, Ling GSF et at. Practice guideline update recommendations summary: Disorders of consciousness: Report of the Guideline Development, Dissemination, and Implementation Subcommittee of the American Academy of Neurology; the American Congress of Rehabilitation Medicine; and the National Institute on Disability, Independent Living, and Rehabilitation Research. Neurology 2018, 91(10):450-460.

43. Scolding N, Owen AM, Keown J: Prolonged disorders of consciousness: a critical evaluation of the new UK guidelines. Brain : a journal of neurology 2021.

44. Owen AM, Coleman MR, Boly M, Davis MH, Laureys S, Pickard JD: Detecting awareness in the vegetative state. Science (New York, NY) 2006, 313(5792): 1402.

45. Monti MM, Vanhaudenhuyse A, Coleman MR, Boly M, Pickard JD, Tshibanda L, Owen AM, Laureys S: Willful modulation of brain activity in disorders of consciousness. N Engl J Med 2010, 362(7):579-589.

46. Goldfine AM, Victor JD, Conte MM, Bardin JC, Schiff ND: Determination of awareness in patients with severe brain injury using EEG power spectral analysis. Clin Neurophysio/2011, 122(11):2157-2168.

47. Pan J, Xie Q, Qin P, Chen Y, He Y, Huang H, Wang F, Ni X, Cichocki A, Yu R et al. Prognosis for patients with cognitive motor dissociation identified by brain-computer interface. Brain : a journal of neurology 2020, 143(4):1177-1189. 
medRxiv preprint doi: https://doi.org/10.1101/2022.01.04.22268656; this version posted January 6, 2022. The copyright holder for this preprint (which was not certified by peer review) is the author/funder, who has granted medRxiv a license to display the preprint in perpetuity.

All rights reserved. No reuse allowed without permission.

48. Giacino JT, Fins JJ, Laureys S, Schiff ND: Disorders of consciousness after acquired brain injury: the state of the science. Nat Rev Neuro/2014, 10(2):99-114.

49. Curley WH, Forgacs PB, Voss HU, Conte MM, Schiff ND: Characterization of EEG signals revealing covert cognition in the injured brain. Brain : a journal of neurology 2018, 141(5):1404-1421.

50. Young MJ, Bodien YG, Giacino JT, Fins JJ, Truog RD, Hochberg LR, Edlow BL: The neuroethics of disorders of consciousness: a brief history of evolving ideas. Brain : a journal of neurology 2021. 


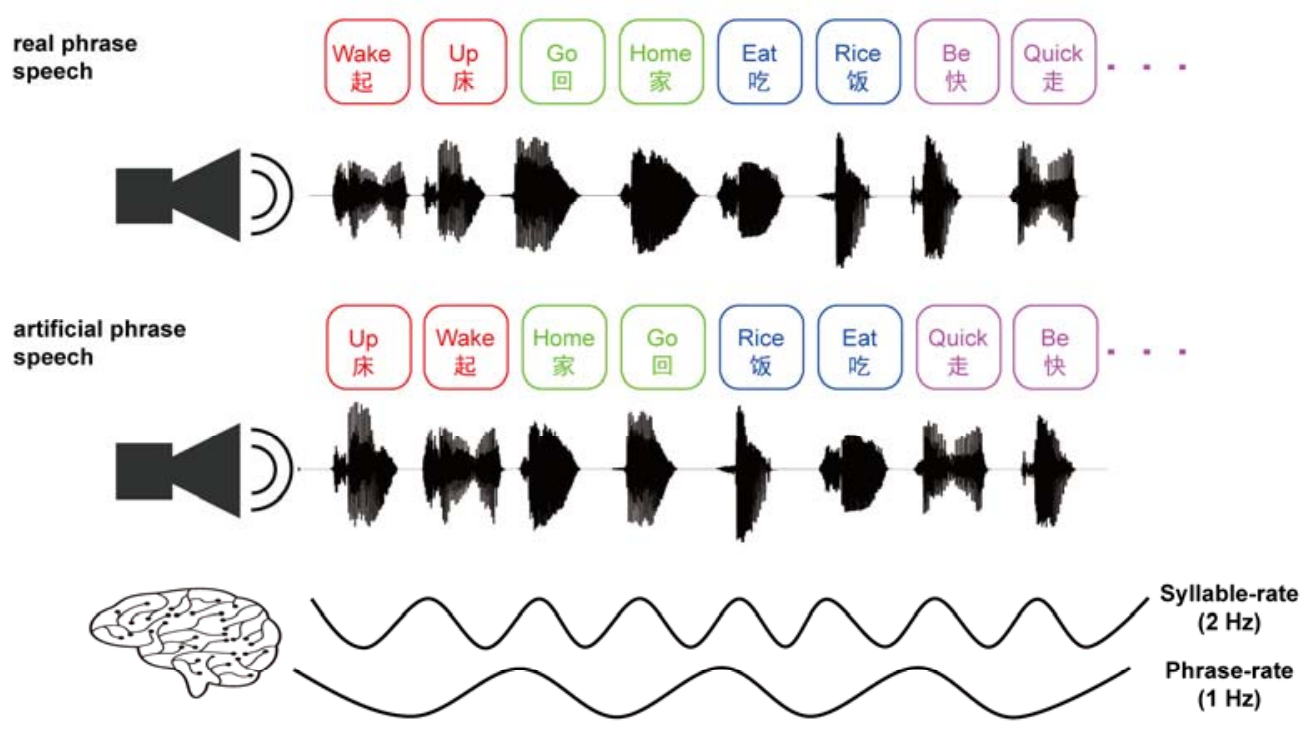

Figure 1. Stimulus. The monosyllabic words were presented at a constant rate of $2 \mathrm{~Hz}$, corresponding to $500 \mathrm{~ms}$ stimuli onset asynchrony (SOA). In the real phrase condition, the stimulus was composed of 4 common 2-word phrases. In the artificial phrase condition, in contrast, the stimulus was composed of 4 artificial 2-word phrases. Each artificial phrase was constructed by reversing the order of the 2 words in a real phrase. 
A

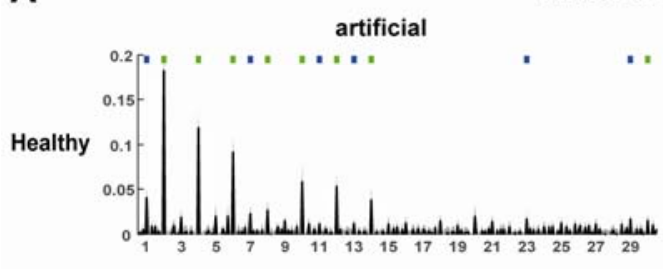

EMCS

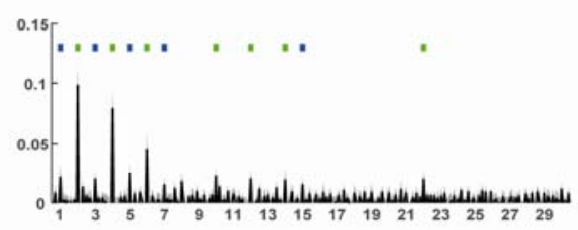

MCS

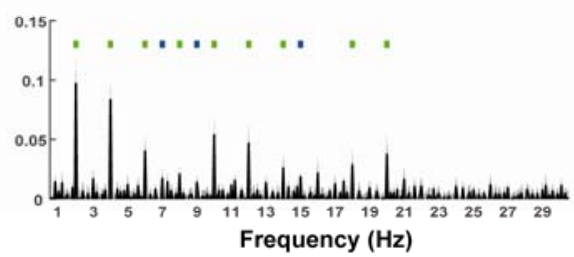

hase coherence spectrum
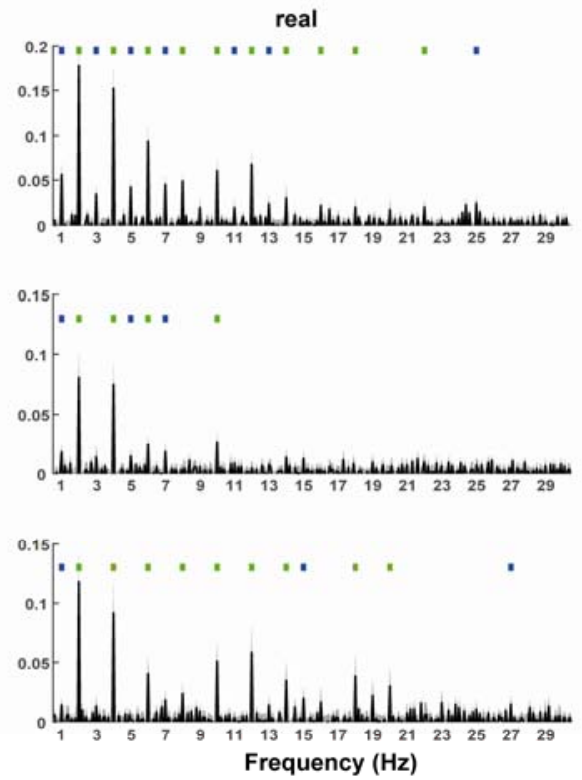

B

Phase coherence at target frequencies
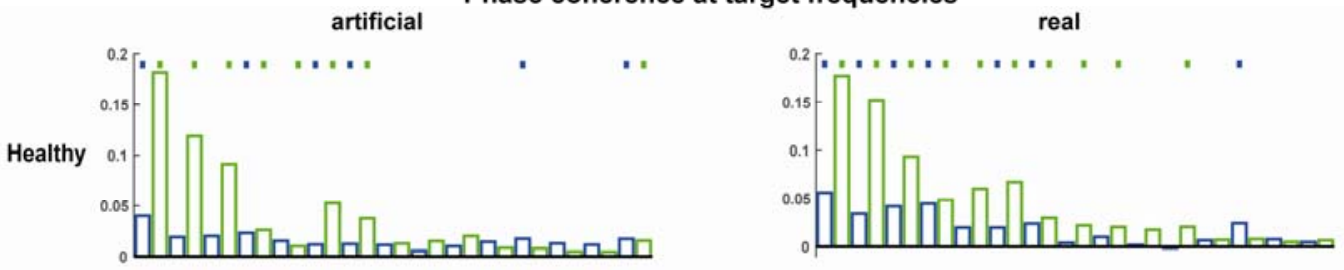

EMCS
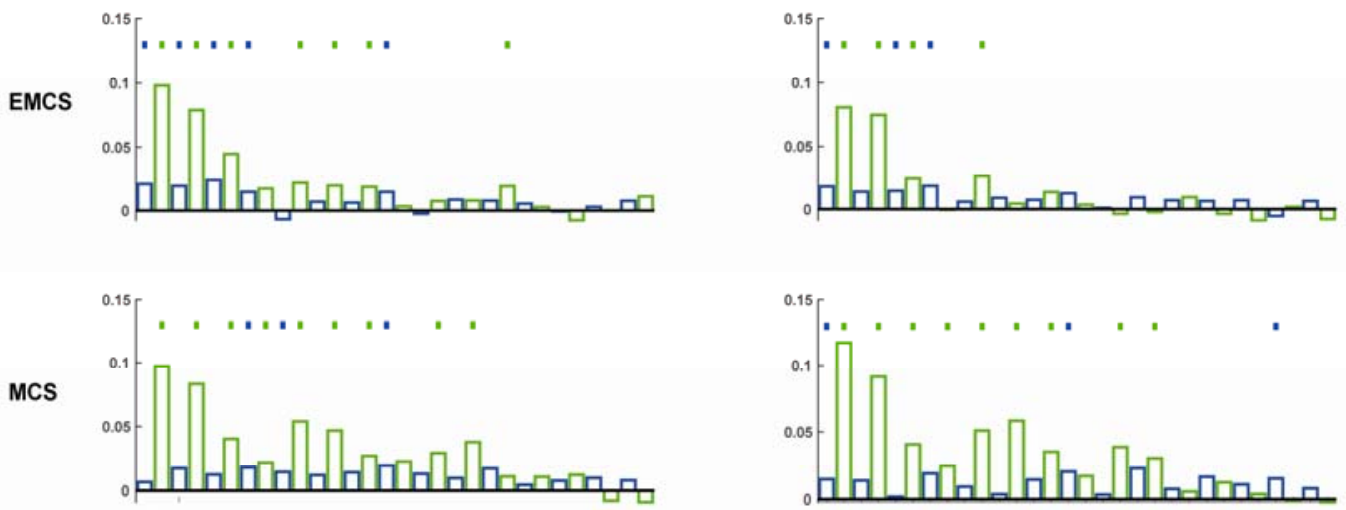

$\square 1,3,5,7 \ldots \ldots . .29 \mathrm{~Hz} \square 2,4,6,8 \ldots \ldots . .30 \mathrm{~Hz}$

Figure 2. ITPC for each participant group. The ITPC at each frequency is normalized by subtracting the mean ITPC averaged over two neighboring frequencies. (A) The phase coherence spectrum for the artificial phrase condition (left) and real phrase condition (right). The spectrum was averaged over all EEG electrodes. The ITPC spectrum shows peaks at the word/phrase rate and harmonically related frequencies, which are further illustrated in panel B. (B) ITPC at target frequencies. If the ITPC is significantly higher than chance, it is marked by a dot. 
A
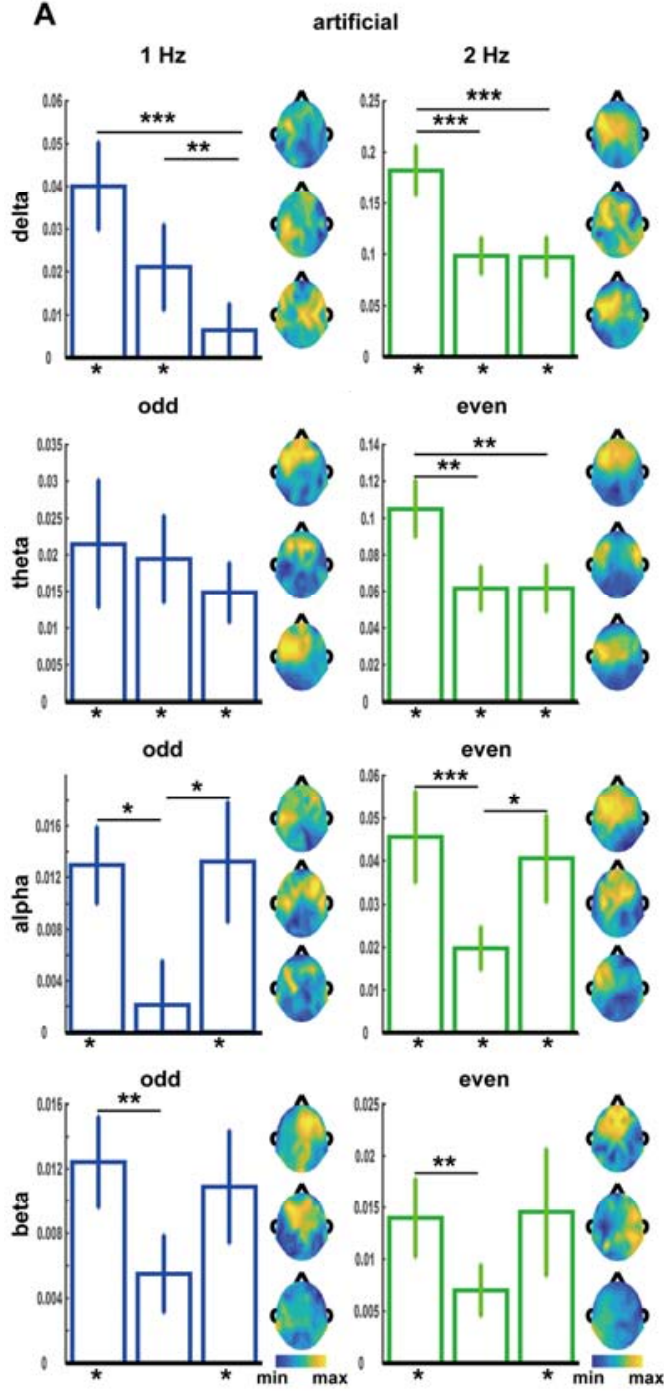

B real
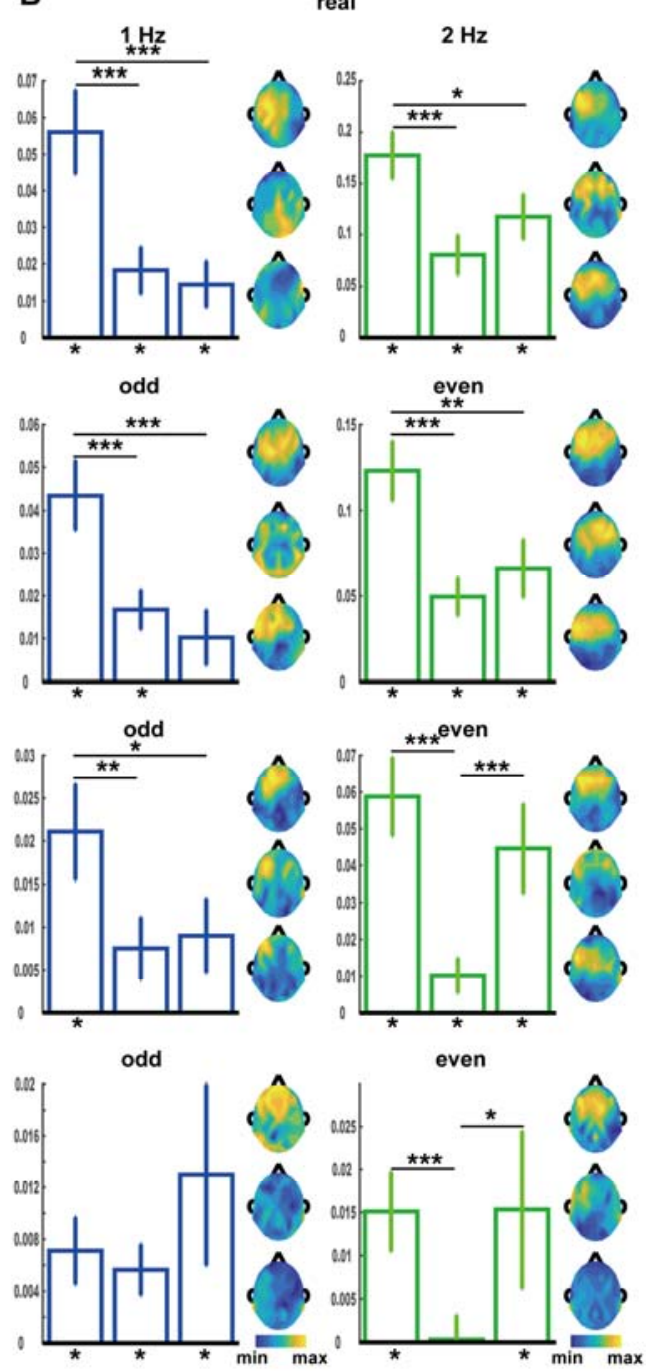

Figure 3. Comparisons of the ITPC across participant groups. The histogram from left to right and the response topography from top to bottom refer to the ITPC in healthy group, EMCS group, and MCS group in turn. The ITPC at the word and phrase rates are shown on the top row. The odd- and even-order harmonics are averaged into 3 frequency bands, i.e., theta $(4-7 \mathrm{~Hz})$, alpha $(8-13 \mathrm{~Hz})$, and beta $(14-30 \mathrm{~Hz})$ and shown in the $2^{\text {nd }}-4^{\text {th }}$ row. Significant differences between populations were indicated by stars on top of each graph. ( ${ }^{*} \mathrm{P}<0.05,{ }^{* *} \mathrm{P}<0.01,{ }^{* * *} \mathrm{P}<0.001$, bootstrap, FDR corrected). The star underlying each bar indicates whether the ITPC is significantly higher than chance $(\mathrm{P}<0.05$, permutation test, FDR corrected). MCS, minimally conscious state; EMCS, emergence from the minimally conscious state. 
Table 1. Two-way ANOVA analysis (condition by group) of ITPC.

\begin{tabular}{|c|c|c|c|c|c|c|c|c|c|c|c|}
\hline \multicolumn{6}{|c|}{$1 \mathrm{~Hz}$} & \multicolumn{6}{|c|}{$2 \mathrm{~Hz}$} \\
\hline \multicolumn{3}{|c|}{ Main effect analysis } & \multicolumn{3}{|c|}{ ANOVA in groups } & \multicolumn{3}{|c|}{ Main effect analysis } & \multicolumn{3}{|c|}{ ANOVA in groups } \\
\hline Conditions & Groups & $\begin{array}{c}\text { Conditions } \\
\text { xgroups }\end{array}$ & $\begin{array}{l}\text { HC vs } \\
\text { EMCS }\end{array}$ & $\begin{array}{l}\text { HC vs } \\
\text { MCS }\end{array}$ & $\begin{array}{c}\text { EMCS vs } \\
\text { MCS }\end{array}$ & Conditions & Groups & $\begin{array}{l}\text { Conditions } \\
\text { xgroups }\end{array}$ & $\begin{array}{l}\text { HC vs } \\
\text { EMCS }\end{array}$ & $\begin{array}{l}\text { HC vs } \\
\text { MCS }\end{array}$ & $\begin{array}{c}\text { EMCS vs } \\
\text { MCS }\end{array}$ \\
\hline .329 & $.000 *$ & .553 & $.001 *$ & $.000 *$ & .229 & .329 & .000* & .553 & $.001 *$ & $.000 *$ & .229 \\
\hline \multicolumn{6}{|c|}{ Theta $(5,7 \mathrm{~Hz})$} & \multicolumn{6}{|c|}{ Theta $(4,6 \mathrm{~Hz})$} \\
\hline \multicolumn{3}{|c|}{ Main effect analysis } & \multicolumn{3}{|c|}{ ANOVA in groups } & \multicolumn{3}{|c|}{ Main effect analysis } & \multicolumn{3}{|c|}{ ANOVA in groups } \\
\hline Conditions & Groups & $\begin{array}{c}\text { Conditions } \\
\text { xgroups }\end{array}$ & $\begin{array}{l}\text { HC vs } \\
\text { EMCS }\end{array}$ & $\begin{array}{l}\text { HC vs } \\
\text { MCS }\end{array}$ & $\begin{array}{c}\text { EMCS vs } \\
\text { MCS }\end{array}$ & Conditions & Groups & $\begin{array}{l}\text { Conditions } \\
\text { xgroups }\end{array}$ & $\begin{array}{l}\text { HC vs } \\
\text { EMCS }\end{array}$ & $\begin{array}{l}\text { HC vs } \\
\text { MCS }\end{array}$ & $\begin{array}{c}\text { EMCS vs } \\
\text { MCS }\end{array}$ \\
\hline .361 & .001* & .083 & $.027 *$ & $.003 *$ & .398 & .779 & .000* & .575 & $.000 *$ & $.001 *$ & .566 \\
\hline \multicolumn{6}{|c|}{ Alpha $(9,11,13 \mathrm{~Hz})$} & \multicolumn{6}{|c|}{ Alpha $(8,10,12 \mathrm{~Hz})$} \\
\hline \multicolumn{3}{|c|}{ Main effect analysis } & \multicolumn{3}{|c|}{ ANOVA in groups } & \multicolumn{3}{|c|}{ Main effect analysis } & \multicolumn{3}{|c|}{ ANOVA in groups } \\
\hline Conditions & Groups & $\begin{array}{c}\text { Conditions } \\
\text { xgroups }\end{array}$ & $\begin{array}{l}\text { HC vs } \\
\text { EMCS }\end{array}$ & $\begin{array}{l}\mathrm{HC} \text { vs } \\
\text { MCS }\end{array}$ & $\begin{array}{c}\text { EMCS vs } \\
\text { MCS }\end{array}$ & Conditions & Groups & $\begin{array}{l}\text { Conditions } \\
\text { xgroups }\end{array}$ & $\begin{array}{l}\text { HC vs } \\
\text { EMCS }\end{array}$ & $\begin{array}{l}\text { HC vs } \\
\text { MCS }\end{array}$ & $\begin{array}{c}\text { EMCS vs } \\
\text { MCS }\end{array}$ \\
\hline .361 & .014* & .316 & $.004 *$ & .168 & -.132 & .735 & $.000 \%$ & .446 & $.000 \%$ & .307 & $-.003^{*}$ \\
\hline \multicolumn{6}{|c|}{ Beta $(15,17 \ldots 29 \mathrm{~Hz})$} & \multicolumn{6}{|c|}{ Beta $(14,16 \ldots 30 \mathrm{~Hz})$} \\
\hline \multicolumn{6}{|c|}{ Main effect analysis } & \multicolumn{3}{|c|}{ Main effect analysis } & \multicolumn{3}{|c|}{ ANOVA in groups } \\
\hline \multicolumn{2}{|c|}{ Conditions } & \multicolumn{2}{|c|}{ Group } & \multicolumn{2}{|c|}{$\begin{array}{c}\text { Conditions } \\
\text { x groups }\end{array}$} & Conditions & Groups & $\begin{array}{l}\text { Conditions } \\
\text { xgroups }\end{array}$ & $\begin{array}{l}\text { HC vs } \\
\text { EMCS }\end{array}$ & $\begin{array}{l}\text { HC vs } \\
\text { MCS }\end{array}$ & $\begin{array}{c}\text { EMCS vs } \\
\text { MCS }\end{array}$ \\
\hline \multicolumn{2}{|c|}{.729} & \multicolumn{2}{|c|}{.202} & \multicolumn{2}{|c|}{.582} & .704 & .043* & .679 & $.033 *$ & .940 & $-.029 *$ \\
\hline
\end{tabular}

*denoted the phase coherence which was statistically significant. HC: healthy controls.

EMCS: patients emerged from the minimally conscious state, MCS: patients in the minimally conscious state. The values in the table indicated the p-value of ANOVA analysis, bold value indicated $\mathrm{P}$ value was less than 0.05 . 